OPEN ACCESS

Edited by:

Nageshwar Reddy Duvvur,

Asian Institute of

Gastroenterology, India

Reviewed by:

Nitin Jagtap,

Asian Institute of

Gastroenterology, India

George Ou,

University of British Columbia, Canada

*Correspondence:

Su Jin Chung

medjsj7@snuh.org

Joo Kyung Park

mdsophie@gmail.com

tThese authors share senior authorship

Specialty section

This article was submitted to

Gastroenterology,

a section of the journal

Frontiers in Medicine

Received: 03 June 2021

Accepted: 23 August 2021

Published: 23 September 2021

Citation:

Chung KH, Park MJ, Jin EH, Seo JY,

Song JH, Yang SY, Kim YS, Yim JY,

Lim SH, Kim JS, Chung SJ and

Park JK (2021) Risk Factors for

High-Risk Adenoma on the First

Lifetime Colonoscopy Using Decision

Tree Method: A Cross-Sectional Study

in 6,047 Asymptomatic Koreans.

Front. Med. 8:719768.

doi: $10.3389 /$ fmed.2021.719768

\section{Risk Factors for High-Risk Adenoma on the First Lifetime Colonoscopy Using Decision Tree Method: A Cross-Sectional Study in 6,047 Asymptomatic Koreans}

Kwang Hyun Chung ${ }^{1}$, Min Jung Park ${ }^{2,3}$, Eun Hyo Jin ${ }^{2}$, Ji Yeon Seo ${ }^{2}$, Ji Hyun Song ${ }^{2}$, Sun Young Yang ${ }^{2}$, Young Sun Kim ${ }^{2}$, Jeong Yoon Yim², Seon Hee Lim $^{2}$, Joo Sung Kim ${ }^{2,4}$, Su Jin Chung ${ }^{2 * t}$ and Joo Kyung Park ${ }^{5,6 * t}$

${ }^{1}$ Division of Gastroenterology, Department of Internal Medicine, Uijeongbu Eulji Medical Center, Eulji University School of Medicine, Uijeongbu, South Korea, ${ }^{2}$ Department of Internal Medicine, Healthcare System Gangnam Center, Healthcare Research Institute, Seoul National University Hospital, Seoul, South Korea, ${ }^{3}$ Department of Internal Medicine, Sheikh Khalifa Specialty Hospital, Ras Al Khaimah, United Arab Emirates, ${ }^{4}$ Department of Internal Medicine and Liver Research Institute, Seoul National University College of Medicine, Seoul, South Korea, ${ }^{5}$ Division of Gastroenterology, Department of Internal Medicine, Samsung Medical Center, Sungkyunkwan University School of Medicine, Seoul, South Korea, ${ }^{6}$ Department of Health Sciences and Technology, Samsung Advanced Institute for Health Sciences and Technology, Sungkyunkwan University, Seoul, South Korea

Background/Aims: As risk of colorectal neoplasm is varied even in persons with "average-risk," risk evaluation and tailored screening are needed. This study aimed to evaluate the risk factors of high-risk adenoma (HRA) in healthy individuals and determine the characteristics of advanced neoplasia (AN) among individual polyps.

Methods: Asymptomatic adults who underwent the first lifetime screening colonoscopy at the Seoul National University Hospital Healthcare System Gangnam Center (SNUH GC) were recruited from 2004 to 2007 as SNUH GC Cohort and were followed for 10 years. Demographic and clinical characteristics were compared between the subjects with and without $A N(\geq 10 \mathrm{~mm}$ in size, villous component, and/or high-grade dysplasia and/or cancer) or HRA (AN and/or 3 or more adenomas). For individual polyps, correlations between clinical or endoscopic features and histologic grades were evaluated using a decision tree method.

Results: A total of 6,047 subjects were included and 5,621 polyps were found in 2,604 $(43 \%)$ subjects. Advanced age, male sex, and current smoking status were statistically significant with regards to AN and HRA. A lower incidence of AN was observed in subjects taking aspirin. In the decision tree model, the location, shape, and size of the polyp, and sex of the subject were key predictors of the pathologic type. A weak but significant association was observed between the prediction of the final tree and the histological grouping (Kendall's tau-c $=0.142, p<0001$ ).

Conclusions: Advanced neoplasia and HRA can be predicted using several individual characteristics and decision tree models.

Keywords: colonic polyps, colonic neoplasms, risk factors, mass screening (MeSH), decision tree method 


\section{INTRODUCTION}

Colon cancer is the third most prevalent cancer and the second leading cause of cancer-related deaths worldwide (1). Like many other cancers, early detection is key to colorectal cancer treatment. Early stages of colon cancer usually require less extensive treatment and can result in better clinical outcomes $(2,3)$. Most colorectal cancers can be prevented by early detection and removal of precursor colorectal adenomas (36). Colonoscopy is one of the most sensitive and effective diagnostic modalities that can directly visualize colorectal lesions and remove premalignant adenomatous polyps or early cancers. However, colonoscopy requires a skilled examiner and is associated with significant costs, inconvenience, and procedurerelated adverse events. These limitations of colonoscopy may decrease adherence to screening tests (7).

Current guidelines recommend that average-risk individuals start colorectal cancer screening at the age of 50 years unless they have the following risk factors: personal history of adenomatous polyps or colorectal cancer, family history of colorectal cancer, confirmed or suspected hereditary colorectal cancer syndrome (such as familial adenomatous polyposis or Lynch syndrome), personal history of abdominal or pelvic radiation for previous cancer, or personal history of inflammatory bowel disease (8, 9). However, there is surmounting evidence that the risk of colorectal neoplasm varies even in average-risk individuals. Precise evaluation of these risks may help to tailor colorectal cancer screening strategies and increase adherence to the screening program.

The aims of this large-scale cross-sectional study were to (1) evaluate the risk factors for advanced neoplasia (AN), and high-risk adenoma (HRA), and (2) determine the characteristics of polyps with advanced histology in healthy asymptomatic individuals from the first lifetime colonoscopy screening.

\section{MATERIALS AND METHODS}

\section{Study Population}

Asymptomatic healthy adults who underwent screening colonoscopy at the Seoul National University Hospital Healthcare System Gangnam Center between October 2004 and June 2007 were recruited for participation in this study. To be included in the study, subjects were required to meet the following criteria: (1) first-lifetime screening colonoscopy, (2) asymptomatic volunteers aged over 20 years, and (3) complete clearing colonoscopy. A complete clearing colonoscopy was defined as colonoscope insertion into the cecum, above fair grade preparation with the Aronchick Bowel Preparation Scale (10), and removal of all detected polyps. In the case of a remnant polyp or poor grade preparation, the procedure was repeated within 6 months. All participants were requested to complete a structured questionnaire on gastrointestinal symptoms and medical histories. Further information was ascertained by endoscopists regarding the reasons for colonoscopy and prior diagnosis of colorectal polyps. Subjects who did not complete the questionnaire were excluded. Based on responses to the questionnaire, the following cases were excluded: colorectal disease-related symptoms or signs (e.g., recent bowel habit change, unexplained weight loss, anemia, and lower gastrointestinal tract bleeding not attributable to hemorrhoids), personal history of colorectal cancer or polyps, surgical resection of the colon or rectum, inflammatory bowel disease or intestinal tuberculosis, and coagulopathy which hinders endoscopic polyp resection.

The study protocol conformed to the ethical guidelines of the 1975 Declaration of Helsinki and its revisions and was approved by the Institutional Review Board of SNUH (No. 0709-025-218). Since the current study was performed with a retrospective design using a database and medical records, informed consent was waived by the board.

\section{Study Procedures and Definitions}

Conventional white light colonoscopes (CF-H260 series; Olympus Co., Ltd., Aizu, Japan/ EC-450HL5, EC-450WM5, or EC-590ZW series; Fujinon Inc., Saitama, Japan) were used in all procedures. All colonoscopies were performed by 15 board-certified endoscopists who had experienced more than 5,000 colonoscopies (at least 500 polypectomies) and achieved an overall adenoma detection rate of over $30 \%$ in routine procedures.

Complete colonoscopy was defined as cecal endoscopic intubation with photo documentation of the appendiceal orifice. Colonoscopy reports provided information on the number, location, shape [according to the Paris classification (11)], and size (estimated with opened biopsy forceps or measured after resection) of the polyps. All detected polyps were completely removed. Diminutive polyps of $<5 \mathrm{~mm}$ were removed using biopsy forceps, larger polyps were removed by endoscopic mucosal resection, and some very large polyps were removed by piecemeal endoscopic mucosal resection or endoscopic submucosal dissection. Specimens from all polyps were reviewed and a confirmatory diagnosis was made by two expert gastrointestinal pathologists, who classified colorectal neoplasms according to the WHO criteria (12). Findings were stratified by the most advanced lesion found (e.g., adenoma with the greatest diameter or the most serious histology). Serrated adenomas were excluded from the analysis. This is because there was no clear criterion for the size of serrated polyps. Further, there was no generally accepted definition for sessile serrated polyps during the period in which the actual endoscopic exam was performed, and an inconsistency in the diagnostic application for serrated adenoma between each pathologist was considered. Pathologic interpretation of intramucosal carcinoma or carcinoma in situ was categorized as high-grade dysplasia and non-neoplastic findings such as lipoma, lymphoid aggregates, or inflammatory polyps were considered normal mucosa and classified as "non-specific lesion" for histologic groups. AN was defined as an adenoma $\geq 10 \mathrm{~mm}$, adenoma with tubulovillous or villous histology and, with high-grade dysplasia, or the presence of invasive cancer (13). HRA was defined as an AN or a case in which three or more adenomas were found in one person (13). To analyze the risk of AN in each polyp, each polyp was classified into four histologic groups: "non-specific lesion," "hyperplastic 
polyp," "non-advanced adenoma," (including low-grade tubular adenoma), and "advanced neoplasia."

\section{Assessment of Risk Variables}

Structured self-administered questionnaires were reviewed for gastrointestinal symptoms and medical history including current smoking (smoked regularly during the previous 12 months), alcohol consumption ( $\geq 70 \mathrm{~g} /$ week), and regular consumption or use (i.e., medication for $\geq 3$ months during the preceding 12 months) of aspirin or non-steroidal anti-inflammatory drugs (NSAIDs), 3-hydroxy-3-methylglutaryl CoA reductase inhibitor (statin), or hormonal replacement therapy. The questionnaires also asked about family history of any cancer including colorectal cancer (at least one first-degree relative with colorectal cancer diagnosed at any age), educational qualification, and monthly household income. Household income was divided into upper and lower classes based on $\$ 50,000$ per year. Physical examinations for all subjects were performed on the day of colonoscopy by trained nurses using a written systematic protocol with standardized instruments. Body mass index (BMI) was calculated from measured weight and height, and categorized as normal $\left(<23 \mathrm{~kg} / \mathrm{m}^{2}\right)$, overweight $\left(23-24.9 \mathrm{~kg} / \mathrm{m}^{2}\right)$, or obese $\left(\geq 25 \mathrm{~kg} / \mathrm{m}^{2}\right)$ according to the WHO Western Pacific Regional Office proposal (14). Waist circumference was measured at the WHO recommended site (midpoint between the lower border of the rib cage and iliac crest), and subjects whose waist circumference was $\geq 90 \mathrm{~cm}$ in men and $\geq 80 \mathrm{~cm}$ in women were classified as having central obesity according to the definition of the Asian population (15). All colonoscopy, pathology reports and medical records were collected from a database (Healthwatch version 2.0).

\section{Statistical Analysis}

Continuous variables were expressed as mean \pm standard deviation. Nominal and ordinal variables are stated as proportions and percentages. To compare the characteristics of individuals with and without AN or HRA, the chi-square test or Fisher's exact test was used for categorical variables, and Student's $t$-test was used for continuous variables after normal distribution was confirmed by performing the AndersonDarling test. To identify the factors related to HRA or AN,

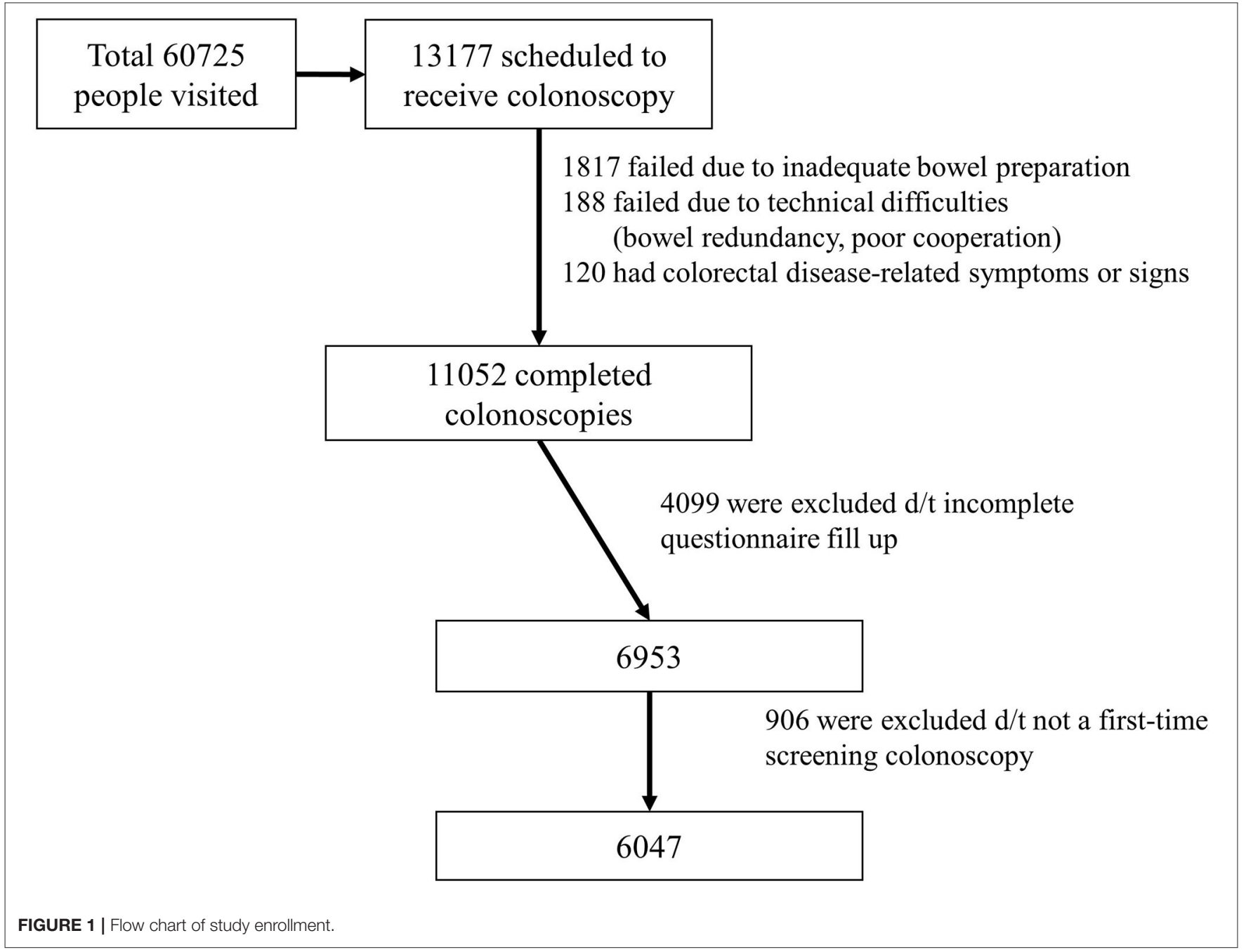


subjects with or without HRA or AN were compared in subjects without a family history of colorectal cancer and adenoma and no positive findings in other tests as a univariate analysis. These variables included the following: age, sex, body mass index, waist circumference, smoking, alcohol, aspirin and/or NSAIDs, statin use, hormone replacement therapy, family history of colorectal cancer, education level, and household income. Variables found to be significant in univariate analysis were subsequently assessed using binary logistic regression with backward elimination method as a multivariate analysis. For each variable, the hazard ratio (HR) and $95 \%$ confidence interval (CI) were calculated. Differences were statistically significant when the two-tailed $p$-value was $<0.05$. R software ( $\mathrm{R}$ for Windows V.4.0.2; The R Foundation

TABLE 1 | Baseline characteristics of the study population.

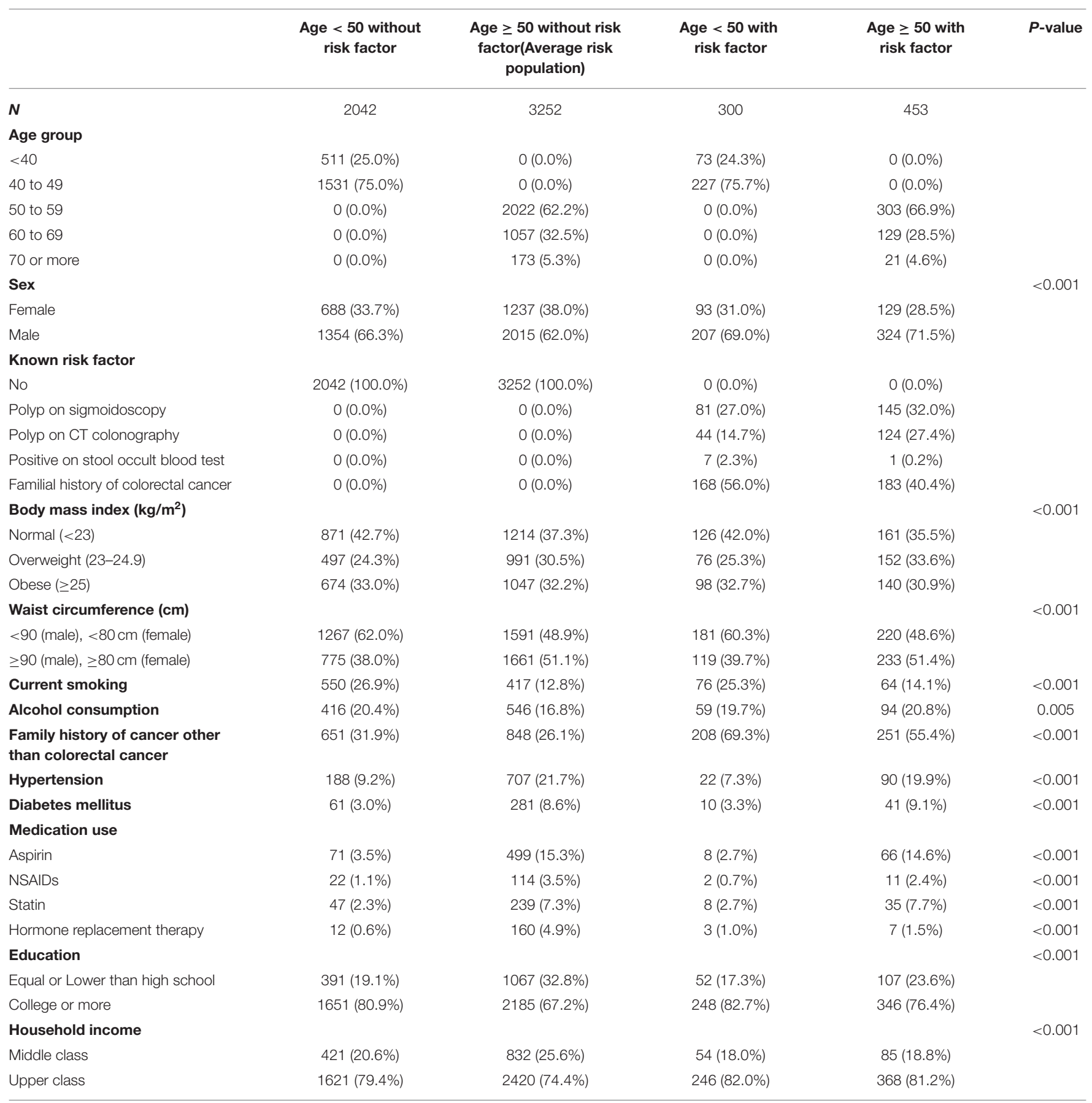

NSAID, non-steroidal anti-inflammatory drugs. 


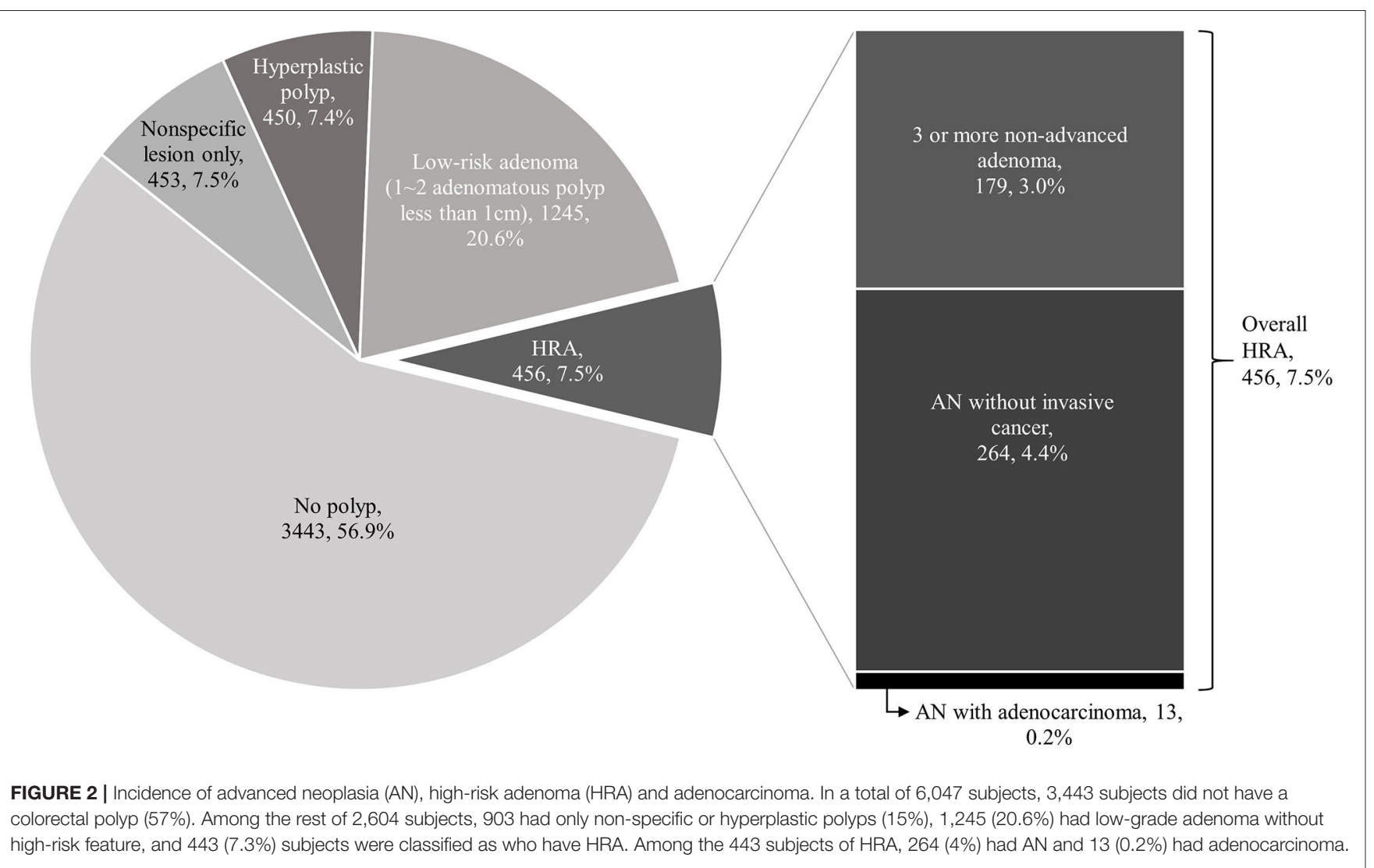

for Statistical Computing, Vienna, Austria) was used for statistical analyses.

Decision tree analysis (16) was conducted to examine the factors associated with polyps, which are AN. As classification variables in the decision tree analysis, factors showing significant differences among the four histological groups mentioned above were considered. Then the final decision tree was estimated using the minimum value of the complexity parameter. The association between prediction from the final tree and histology grouping was checked with Kendall's tau-c and its $95 \%$ confidence interval. The decision tree analysis was supported by the Statistics and Data Center at Samsung Medical Center using the Recursive Partitioning and Regression Trees (rpart) package in R software (version 3.2.3).

\section{RESULTS}

\section{Clinical and Socioeconomic Characteristics of Subjects}

During the study period, 60,725 people visited the institution of the researchers for routine health check-ups, and 13,177 patients were scheduled to undergo screening colonoscopy. Of these, 120 were excluded from the analysis because of colorectal disease-related symptoms or signs, 188 were excluded because the cecum could not be reached due to technical difficulties (bowel redundancy and/or poor cooperation), and 1,817 were excluded from the study due to inadequate bowel preparation. A number of 11,052 people completed screening colonoscopies and 4,099 people were excluded because of incomplete questionnaires. Of the 6,953 people remaining, 906 were excluded because they were not first-time screening colonoscopies. A total of 6,047 subjects who underwent the first lifetime colonoscopy were included and analyzed in this study (Figure 1).

The clinical and socioeconomic characteristics of the study population are described in Table 1. The study population included 5,294 subjects with no risk factors. Of these, 3,252 were over 50 years of age and 2,042 subjects were under 50 years of age. A total of 753 subjects showed some risk such as a family history of colorectal cancer or adenoma or had a positive result in other tests, of which 300 were under the age of 50 and 453 were over the age of 50 .

\section{Colonoscopic Features and Histopathologic Findings}

Of the 6,047 enrolled subjects, 1,245 (20.6\%) had low-grade adenoma without high-risk features, and 456 (7.5\%) subjects were classified as having HRA. Among the 456 subjects with HRA, 277 (4.6\%) had AN and $13(0.2 \%)$ had adenocarcinoma (Figure 2). The endoscopic and pathologic characteristics of polyps are shown in Table 2. Overall, 1,701 (28.1\%) subjects had at least one adenoma, 1,435 (23.7\%) subjects had one or two adenomas, and $266(4.4 \%)$ subjects had three or more. Histologic features of the most advanced lesions were as follows: $1,555(59.7 \%)$ subjects had low-grade adenomas, 
TABLE 2 | Colonoscopy findings and histopathologic results of polyps.

\begin{tabular}{|c|c|}
\hline Total subject number & 6047 \\
\hline \multicolumn{2}{|l|}{ Number of polyps per subjects } \\
\hline 0 & $3443(56.9 \%)$ \\
\hline $1-2$ & $1963(32.5 \%)$ \\
\hline$\geq 3$ & $641(10.6 \%)$ \\
\hline \multicolumn{2}{|l|}{ Number of adenomas per subjects } \\
\hline 0 & $4346(71.9 \%)$ \\
\hline $1-2$ & $1435(23.7 \%)$ \\
\hline$\geq 3$ & $266(4.4 \%)$ \\
\hline \multicolumn{2}{|c|}{ Histologic features of most advanced lesion of each subject } \\
\hline Non-specific lesion & $453(17.4 \%)$ \\
\hline Hyperplastic polyp & $450(17.3 \%)$ \\
\hline Tubular adenoma & $1555(59.7 \%)$ \\
\hline Tubulovillous/villous adenoma & $113(4.3 \%)$ \\
\hline High-grade dysplasia & $20(0.8 \%)$ \\
\hline Adenocarcinoma & $13(0.5 \%)$ \\
\hline \multicolumn{2}{|c|}{$\begin{array}{l}\text { Characteristics of the most advanced lesion in subjects } \\
\text { with adenomatous polyp }\end{array}$} \\
\hline \multicolumn{2}{|c|}{ Location } \\
\hline Ascending colon & $446(26.2 \%)$ \\
\hline Transverse colon & 494 (29.0\%) \\
\hline Descending colon & $182(10.7 \%)$ \\
\hline Sigmoid colon & $418(24.6 \%)$ \\
\hline Rectum & $161(9.5 \%)$ \\
\hline \multicolumn{2}{|l|}{ Size } \\
\hline $1-5 \mathrm{~mm}$ & 974 (57.3\%) \\
\hline $6-9 \mathrm{~mm}$ & $507(29.8 \%)$ \\
\hline$\geq 10 \mathrm{~mm}$ & $220(12.9 \%)$ \\
\hline \multicolumn{2}{|l|}{ Shape } \\
\hline 0-Is (sessile) & $1266(74.5 \%)$ \\
\hline 0-Isp (subpedunculated) & $272(16.0 \%)$ \\
\hline 0-Ip (pedunculated) & $132(7.8 \%)$ \\
\hline 0-lla,b,c (non-polypoid) & $29(1.7 \%)$ \\
\hline Invasive cancer (mass or ulcerative cancer) & $2(0.1 \%)$ \\
\hline Total polyp number & 5618 \\
\hline \multicolumn{2}{|l|}{ Histologic features of each polyp } \\
\hline Non-specific lesion & $1492(26.6 \%)$ \\
\hline Hyperplastic polyp & $1085(19.3 \%)$ \\
\hline Tubular adenoma & $2882(51.3 \%)$ \\
\hline Tubulovillous adenoma & $125(2.2 \%)$ \\
\hline High-grade dysplasia & $21(0.4 \%)$ \\
\hline Adenocarcinoma & $13(0.2 \%)$ \\
\hline \multicolumn{2}{|l|}{ Endoscopic features of each polyp } \\
\hline \multicolumn{2}{|l|}{ Location } \\
\hline Ascending colon & $1351(24.0 \%)$ \\
\hline Transverse colon & $1457(25.9 \%)$ \\
\hline Descending colon & $545(9.7 \%)$ \\
\hline Sigmoid colon & $1323(23.5 \%)$ \\
\hline Rectum & $942(16.8 \%)$ \\
\hline \multicolumn{2}{|l|}{ Size } \\
\hline $1-5 \mathrm{~mm}$ & 4243 (75.5\%) \\
\hline $6-9 \mathrm{~mm}$ & $1068(19.0 \%)$ \\
\hline$\geq 10 \mathrm{~mm}$ & 305 (5.4\%) \\
\hline
\end{tabular}

(Continued)
TABLE 2 | Continued

$\begin{array}{lc}\text { Shape } & \\ \text { 0-Is (sessile) } & 4781(85.1 \%) \\ \text { 0-Isp (subpedunculated) } & 526(9.4 \%) \\ \text { O-Ip (pedunculated) } & 210(3.7 \%) \\ \text { O-lla,b,c (non-polypoid) } & 99(1.8 \%) \\ \text { Invasive cancer (mass or ulcerative cancer) } & 2(<0.1 \%)\end{array}$

and $113(4.3 \%)$ subjects had tubulovillous adenoma. Twenty (0.8\%) subjects had high-grade dysplasia and $13(0.5 \%)$ subjects had adenocarcinoma. In patients with colorectal neoplasm, the most advanced lesion was located in the ascending colon in $446(26.2 \%)$ subjects, transverse colon in $494(29.0 \%)$ subjects, descending colon in $182(10.7 \%)$ subjects, sigmoid colon in $418(24.6 \%)$ subjects, and rectum in 161 (9.5\%) subjects. More than half of the most advanced lesions were $\leq 5 \mathrm{~mm}$ and $12.9 \%$ were $\geq 10 \mathrm{~mm}$. The shape of the most advanced lesions was 0-Is (sessile) in 1,266 (74.5\%) subjects, 0-Isp (subpedunculated) in 272 (16.0\%) subjects, and 0-Ip (pedunculated) in 132 (7.8\%) subjects.

\section{Factors Associated in Patients With AN or HRA}

Univariate analysis of risk factors for AN and HRA was performed on subjects with no known risk factors (familial history of colorectal cancer or adenoma, positive on other screening modalities) and are described in Table 3. The mean age of subjects with AN or HRA were higher than the mean age of subjects without AN or HRA ( $52.0 \pm 9.6$ vs. $57.7 \pm 8.8, p<0.001$ for AN, and $51.8 \pm 9.5$ vs. $58.2 \pm 8.7, p<0.001$ for HRA). Male sex was a significant risk factor for both AN and HRA. Factors significantly increased the risk of HRA included current smoking, heavy alcohol consumption, family history of cancers other than colorectal cancer, hypertension. The use of NSAIDs or aspirin decreased the risk of HRA.

In multivariate analysis, factors significantly increased the risk of AN were advanced age, male sex, and current smoking. Aspirin use is associated with decreased AN. Factors related to HRA included advanced age, male sex, and current smoking. However, aspirin or NSAIDs, HRT, and statin use were not related to HRA. Other factors that are expected to be related to advanced colorectal neoplasms such as obesity, individual component and/or presence or absence of metabolic syndrome, or alcohol consumption were not significantly related to AN or HRA. Socioeconomic status including education or household income did not relate to higher rates of AN and HRA (Table 4).

\section{Prediction of the Histological Findings of Individual Polyps}

Differences in the histology of polyps according to demographic and endoscopic features are described in Table 5. The age of subjects tended to be higher in accordance with pathologic grade (55.2 to 57.9, $p<$ 0.001). Polyps in the proximal colon tended to be more adenomatous polyps (non-advanced adenoma + AN) (61.8 
TABLE 3 | Factors associated with AN or HRA according to univariate analysis.

\begin{tabular}{|c|c|c|c|c|c|c|}
\hline & Without AN & With AN & $P$-value & Without HRA & With HRA & $P$-value \\
\hline No. & 5066 & 228 & & 4921 & 373 & \\
\hline Age (mean \pm SD) (years) & $52.0 \pm 9.6$ & $57.7 \pm 8.8$ & $<0.001$ & $51.8 \pm 9.5$ & $58.2 \pm 8.7$ & $<0.001$ \\
\hline Sex (male) & $3200(63.2 \%)$ & 169 (74.1\%) & 0.001 & 3071 (62.4\%) & 298 (79.9\%) & $<0.001$ \\
\hline Body mass index $\left(\mathrm{kg} / \mathrm{m}^{2}\right)$ & & & 0.818 & & & 0.350 \\
\hline Normal (<23) & 1992 (39.3\%) & $93(40.8 \%)$ & & 1949 (39.6\%) & $136(36.5 \%)$ & \\
\hline Waist circumference (cm) & & & 0.643 & & & 0.989 \\
\hline$<90$ (male), $<80 \mathrm{~cm}$ (female) & $2731(53.9 \%)$ & $127(55.7 \%)$ & & 2656 (54.0\%) & $202(54.2 \%)$ & \\
\hline$\geq 90$ (male), $\geq 80 \mathrm{~cm}$ (female) & $2335(46.1 \%)$ & $101(44.3 \%)$ & & 2265 (46.0\%) & $171(45.8 \%)$ & \\
\hline Smoking & $914(18.0 \%)$ & $53(23.2 \%)$ & 0.057 & $868(17.6 \%)$ & $99(26.5 \%)$ & $<0.001$ \\
\hline Alcohol & $912(18.0 \%)$ & $50(21.9 \%)$ & 0.157 & $873(17.7 \%)$ & $89(23.9 \%)$ & 0.004 \\
\hline \multicolumn{7}{|l|}{ Medication use } \\
\hline Aspirin & $553(10.9 \%)$ & $17(7.5 \%)$ & 0.124 & $518(10.5 \%)$ & $52(13.9 \%)$ & 0.049 \\
\hline NSAIDs & $128(2.5 \%)$ & $8(3.5 \%)$ & 0.482 & $120(2.4 \%)$ & $16(4.3 \%)$ & 0.045 \\
\hline Statin & $275(5.4 \%)$ & $11(4.8 \%)$ & 0.807 & $264(5.4 \%)$ & $22(5.9 \%)$ & 0.749 \\
\hline HRT & $167(3.3 \%)$ & $5(2.2 \%)$ & 0.466 & $166(3.4 \%)$ & $6(1.6 \%)$ & 0.089 \\
\hline Education (college or more) & $3675(72.5 \%)$ & $161(70.6 \%)$ & 0.574 & $3563(72.4 \%)$ & $273(73.2 \%)$ & 0.789 \\
\hline Household income (upper class) & 3878 (76.5\%) & $163(71.5 \%)$ & 0.093 & 3771 (76.6\%) & $270(72.4 \%)$ & 0.072 \\
\hline
\end{tabular}

AN, advanced neoplasia; BMI, body mass index; CRC, colorectal cancer; F, female; HRA, high-risk adenoma; HRT, hormone replacement therapy; M, male; NSAID, non-steroidal anti-inflammatory drugs; SD, Standard deviation.

TABLE 4 | Factors associated with AN or HRA according to multivariate analysis.

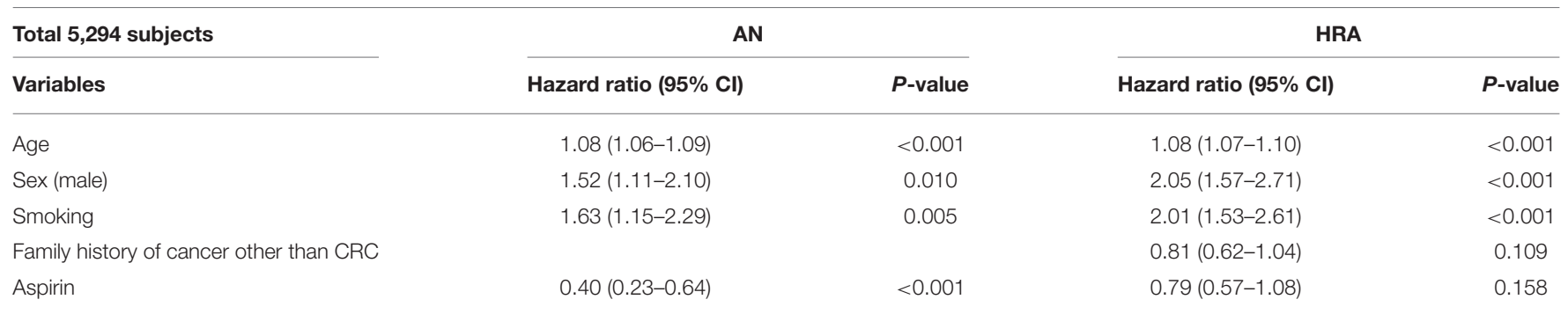

AN, advanced neoplasia; CRC, colorectal cancer; HRA, high-risk adenoma.

vs. $35.8 \%$ ), but the proportion of $\mathrm{AN}$ was higher in the rectosigmoid colon (2.0 vs. $4.1 \%)$. The polyp size tended to increase as the pathologic grade advanced. Compared with hyperplastic polyps, adenomatous polyps tended to be more pedunculated (Isp to Ip), and polyps with AN were even more common.

According to the multivariate analysis performed via the decision tree analysis, location, size, sex, and polyp shape were selected in the final decision tree with five leaf nodes (Figure 3) and considered to be significantly related to polyp histology. Knowing the location of the polyp was the first step in predicting polyp histology and polyps $>5 \mathrm{~mm}$ in the rectosigmoid area constituted the highest proportion of adenomatous polyps (72.9\%) and AN (16.5\%). Polyps $<5 \mathrm{~mm}$ in the rectosigmoid area and polyps in female subjects revealed a low probability of adenomatous polyps (41.2\%) and $\mathrm{AN}$ (1.5\%). In male subjects, polyps shaped 0-Isp (subpedunculated) or 0-Ip (pedunculated) showed the second highest probability of being $\mathrm{AN}$ (5\%). However, 0-Is (sessile) or flat polyps had the lowest probability of being $\mathrm{AN}(0.3 \%)$. In polyps located in the proximal colon, the probability of being a non-advanced adenoma was relatively high (63.8\%), but the probability of being AN was low (2\%). A significant but weak association was observed between prediction from the final tree and histology grouping (Kendall's tau-c $=0.142$, $p<0.0001)$. 
TABLE 5 | Clinical and endoscopic factors associated with advanced neoplasia (AN).

\begin{tabular}{|c|c|c|c|c|c|}
\hline & Non-specific lesion & Hyperplastic polyp & Non-advanced adenoma & Advanced neoplasia & $P$-value \\
\hline Age & $55.2 \pm 8.9$ & $54.1 \pm 9.0$ & $56.8 \pm 8.9$ & $57.9 \pm 9.2$ & $<0.001$ \\
\hline Sex & & & & & $<0.001$ \\
\hline Male & $1164(25.8 \%)$ & $907(20.1 \%)$ & $2326(51.6 \%)$ & $109(2.4 \%)$ & \\
\hline Female & 328 (29.5\%) & $178(16.0 \%)$ & $556(50.0 \%)$ & $50(4.5 \%)$ & \\
\hline Indication & & & & & 0.003 \\
\hline Location & & & & & $<0.001$ \\
\hline Proximal & 878 (26.2\%) & 337 (10.1\%) & 2072 (61.8\%) & $66(2.0 \%)$ & \\
\hline Rectosigmoid & $614(27.1 \%)$ & $748(33.0 \%)$ & $810(35.8 \%)$ & $93(4.1 \%)$ & \\
\hline Size & & & & & $<0.001$ \\
\hline $1-5 \mathrm{~mm}$ & 1326 (31.3\%) & $892(21.0 \%)$ & $2004(47.2 \%)$ & $21(0.5 \%)$ & \\
\hline Flat & 33 (33.3\%) & $24(24.2 \%)$ & 40 (40.4\%) & $2(2.0 \%)$ & \\
\hline Is & $1348(28.2 \%)$ & $995(20.8 \%)$ & $2393(50.1 \%)$ & 45 (0.9\%) & \\
\hline Isp & 75 (14.3\%) & 59 (11.2\%) & 329 (62.5\%) & $63(12.0 \%)$ & \\
\hline Ip & $36(17.1 \%)$ & 7 (3.3\%) & $120(57.1 \%)$ & $47(22.4 \%)$ & \\
\hline Mass & $0(0 \%)$ & $0(0 \%)$ & $0(0 \%)$ & $2(100.0 \%)$ & \\
\hline Body mass index $\left(\mathrm{kg} / \mathrm{m}^{2}\right)$ & & & & & 0.002 \\
\hline Normal $(<23)$ & 437 (24.9\%) & $329(18.7 \%)$ & $919(52.4 \%)$ & $70(4.0 \%)$ & \\
\hline Overweight (23-24.9) & $448(26.3 \%)$ & $315(18.5 \%)$ & $901(52.9 \%)$ & $40(2.3 \%)$ & \\
\hline Obese $(\geq 25)$ & $607(28.1 \%)$ & $441(20.4 \%)$ & 1062 (49.2\%) & $49(2.3 \%)$ & \\
\hline Waist circumference (cm) & & & & & 0.007 \\
\hline$<90$ (male), $<80 \mathrm{~cm}$ (female) & $757(25.2 \%)$ & $625(20.8 \%)$ & $1544(51.3 \%)$ & $83(2.8 \%)$ & \\
\hline Family history of colorectal cancer & & & & & 0.048 \\
\hline No & 1394 (26.5\%) & 1005 (19.1\%) & $2713(51.6 \%)$ & $142(2.7 \%)$ & \\
\hline Yes & 98 (26.9\%) & 80 (22.0\%) & 169 (46.4\%) & $17(4.7 \%)$ & \\
\hline $\begin{array}{l}\text { Family history of cancer other than } \\
\text { colorectal cancer }\end{array}$ & & & & & 0.122 \\
\hline No & 1011 (25.9\%) & 746 (19.1\%) & 2042 (52.3\%) & 105 (2.7\%) & \\
\hline Yes & 481 (28.1\%) & 339 (19.8\%) & 840 (49.0\%) & $54(3.2 \%)$ & \\
\hline Hypertension & & & & & 0.2 \\
\hline No & 1196 (26.4\%) & 898 (19.8\%) & 2315 (51.1\%) & $123(2.7 \%)$ & \\
\hline Yes & 296 (27.3\%) & 187 (17.2\%) & 567 (52.2\%) & 36 (3.3\%) & \\
\hline Diabetes mellitus & & & & & 0.094 \\
\hline No & 1371 (26.9\%) & 968 (19.0\%) & $2619(51.3 \%)$ & $148(2.9 \%)$ & \\
\hline Yes & $121(23.6 \%)$ & 117 (22.9\%) & $263(51.4 \%)$ & $11(2.1 \%)$ & \\
\hline \multicolumn{6}{|l|}{ Medication use } \\
\hline Aspirin & & & & & 0.012 \\
\hline No & 1273 (26.4\%) & 941 (19.5\%) & 2461 (51.0\%) & 150 (3.1\%) & \\
\hline Yes & $219(27.6 \%)$ & 144 (18.2\%) & $421(53.1 \%)$ & $9(1.1 \%)$ & \\
\hline
\end{tabular}


TABLE 5 | Continued

\begin{tabular}{|c|c|c|c|c|c|}
\hline & Non-specific lesion & Hyperplastic polyp & Non-advanced adenoma & Advanced neoplasia & $P$-value \\
\hline NSAIDs & & & & & 0.277 \\
\hline No & $1458(26.6 \%)$ & $1064(19.4 \%)$ & $2801(51.2 \%)$ & $153(2.8 \%)$ & \\
\hline Yes & $34(23.9 \%)$ & $21(14.8 \%)$ & $81(57.0 \%)$ & $6(4.2 \%)$ & \\
\hline Statin & & & & & 0.598 \\
\hline No & 1411 (26.7\%) & 1013 (19.2\%) & 2709 (51.3\%) & $148(2.8 \%)$ & \\
\hline No & 1458 (26.4\%) & $1071(19.4 \%)$ & 2834 (51.4\%) & 155 (2.8\%) & \\
\hline Yes & $34(34.0 \%)$ & $14(14.0 \%)$ & $48(48.0 \%)$ & $4(4.0 \%)$ & \\
\hline Highest education & & & & & 0.133 \\
\hline Equal or Lower than high school & 391 (27.5\%) & $250(17.6 \%)$ & 731 (51.5\%) & $48(3.4 \%)$ & \\
\hline College or more & 1101 (26.2\%) & 835 (19.9\%) & 2151 (51.2\%) & $111(2.6 \%)$ & \\
\hline
\end{tabular}

NSAID, non-steroidal anti-inflammatory drugs.

\section{DISCUSSION}

Population-based screening is a key strategy for improving colorectal cancer prognosis and can detect precursor adenomas or colorectal cancer at an early stage $(8,9,17,18)$. Colonoscopy screening for colorectal cancer reduces incidence and colorectal cancer related mortality $(3,6)$. Recent guidelines recommend that colorectal cancer screening in "average-risk subject" starts at age 50 and continues until 75 years of age since colorectal cancer was diagnosed most frequently in patients 65 to 74 years of age (18). However, there is evidence that the risk of colorectal neoplastic polyps and cancer varies among different risk groups (19-24). Therefore, colorectal cancer screening strategies need to be tailored and elaborated, to account for the diverse degree of risk in the individual person.

In this study, various demographic and clinical factors which could easily be gathered in daily medical practice were evaluated as risk factors for advanced colorectal neoplasms in asymptomatic subjects who underwent the first lifetime screening colonoscopy. Advanced age, male sex, and smoking were significant risk factors for both $\mathrm{AN}$ and HRA which is consistent with previous studies (19-22). Interestingly, in the present study, aspirin use decreased the risk of AN, but not HRA. Aspirin may have some protective effect on the progression of low-grade adenoma to AN but not in the development of lowgrade adenoma. The prophylactic effect of aspirin is underrated in low-grade adenomas. Low-grade adenomas were classified as HRA with a number of 3 or more. Even though subjects with advanced colorectal neoplasms tended to have hypertension and diabetes, these factors were not statistically significant. Education level and household income were not statistically significant between the two groups, even though household income was slightly lower in subjects with advanced colorectal neoplasm.

Significant factors, which could predict the histology of individual polyps, were location, size, and shape of the polyp and the sex of the subject. In the model of the study, polyp location was the first and most important step in predicting histology. Proximal polyps had a high rate of adenomatous polyps. However, rectosigmoid polyps were also significant, especially those $>5 \mathrm{~mm}$ in size and had more AN. Even in polyps located in the rectosigmoid area and had a size of $\leq 5 \mathrm{~mm}$, attention is needed in Isp or Ip-shaped polyps of male subjects due to the high proportion of AN.

The distribution of adenomatous polyps within the colon is highly influenced by the characteristics of the study population, such as age or sex $(25,26)$. A previous large retrospective cohort study (27) and a multicenter retrospective cohort study in South Korea (28) showed that polyps in the proximal colon are more likely to be adenomatous polyp than distal polyps, which is consistent with the results. With regard to advanced adenoma, some studies have shown a similar ratio of advanced adenoma $(29,30)$ between the proximal and rectosigmoid colon. Another study reported that polyps $>5 \mathrm{~mm}$ in the rectosigmoid colon are more likely to have advanced adenoma than in the proximal colon (31) which corresponds to the findings of the study. Although adenomatous polyps are more common in the proximal colon, polyps in the rectosigmoid colon should also be investigated because adenomatous polyps in the rectosigmoid colon can be more advanced.

It is already known that a larger polyp size is related to $\mathrm{AN}$ $(29,31-36)$. In the model of the study, size is an important step in determining histologic grade in rectosigmoid polyps. Most previous studies have shown a marked increase in histologic grade at $1 \mathrm{~cm}$ cut off $(33,34,36)$ which is one of the criteria for $\mathrm{AN}(37,38)$. However, the model shows a cutoff of $5 \mathrm{~mm}$ was significant for differentiating each node. In addition, polyps $<5 \mathrm{~mm}$ account for $11.4 \%$ of polyps with high-grade dysplasia or carcinoma.

The shape of the polyp was also an important factor for discriminating histological features in male subjects with a size 


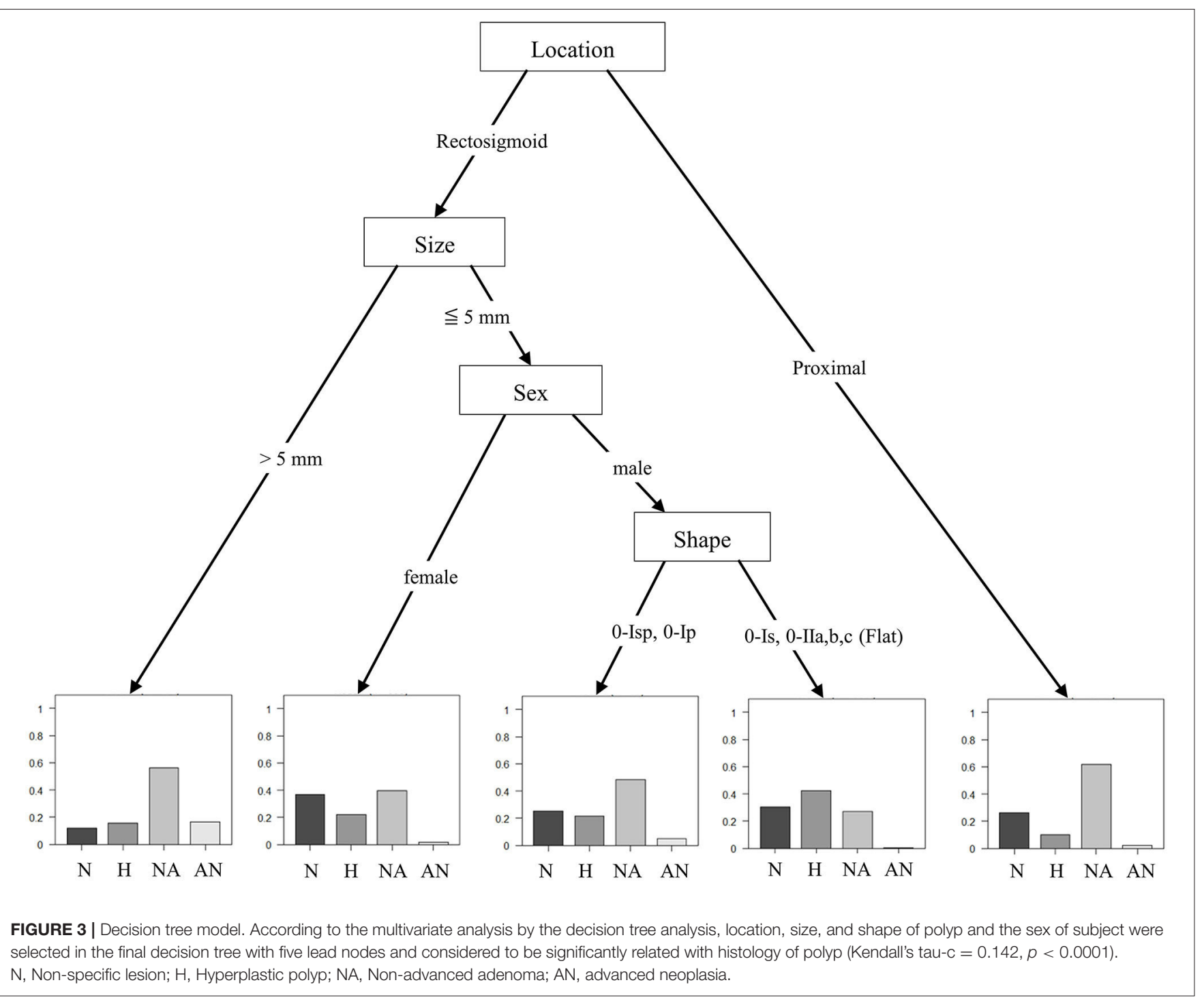

$<5 \mathrm{~mm}$. The 0 -Isp or 0 -Ip type polyps were more likely to be adenomatous or AN than 0-Is polyps or flat lesions. It seems that pedunculated polyps are more likely to be adenomas or ANs than sessile polyps which is consistent with a previous study (33).

In Korean epidemiologic studies, the incidence of rectal adenoma is similar to that of the proximal colon and distal colon adenoma, but advanced polyps are found more frequently in the rectosigmoid colon, and rectal cancer is more common than proximal colon cancer $(39,40)$; thus, rectal polyps should not be overlooked in clinical practice. This fact is consistent with the findings and suggests that even diminutive $(<5 \mathrm{~mm})$ polyps found in the rectosigmoid area should not be taken lightly.

In the study, the adenoma detection rate was relatively low at $28.1 \%(1,047 / 6,047)$ in all subjects, and $28.7 \%(1,517 / 5,294)$ in subjects without previously known risk factors. This may be because many of the included subjects were under 50 years of age. In subjects without risk factors, the adenoma detection rate by age was $17.6 \%(359 / 2,042)$ for those under $50,29.9 \%$ for those in their 50s $(604 / 2,022), 35.6 \%(376 / 1,057)$ for those in their 60s, and $51.4 \%(89 / 173)$ for those over 70 years old. However, adenomas are also found in patients younger than 50 years of age, albeit at a low rate, with $\mathrm{AN}$ in $2 \%$ of study subjects and HRP in approximately $3 \%$ of study subjects in this category. Therefore, screening colonoscopy may be necessary in some cases. According to previous reports, the incidence of adenomatous polyps increases with age $(41,42)$ and the study found that the proportion of adenomas and $\mathrm{AN}$ was higher in the older age group. However, age is not included as a significant factor in the decision tree model, likely due to its low effect. Alcohol consumption, metabolic syndrome (DM, HTN, high BMI, or abdominal obesity), medication use, education, and income were also considered but these factors were not related to an increased incidence of AN or HRP in the first lifetime screening colonoscopy.

The limitations of the study include the retrospective design, and the many demographic data were collected from 
patients' written reports which can be a source of recall bias. However, demographic features or socioeconomic status was investigated before the colonoscopy examination with a validated questionnaire that could minimize recall bias and drawbacks of retrospective design. On the other hand, there may be a risk of selection bias because a large number of subjects were excluded from the study at the beginning of the analysis. However, since most of the subjects were excluded because they did not fill out the questionnaire, and not because of differences in endoscopy results or specific factors, the risk of selection bias was considered to be negligible. Although many cases were excluded, many cases remained which was considered sufficient to answer the research questions. Additionally, serrated adenoma was inevitably excluded, and since this study was conducted at a single institution, there may be some limitations in generalizing the results of this study. Other various optical evaluation methods, such as pit pattern or narrow band image could not be used to distinguish the characteristics of polyps. In the study, a large number of subjects solely within the Asian population were included. All subjects were asymptomatic, and the colonoscopy was a first life time screening which is representative of the main target for screening colonoscopy, the general healthy population. Although this was a retrospective study, the prospective cohort was used, and many factors (e.g., medication use, household income, education) that might affect the incidence of colorectal polyps could be evaluated. The decision tree model in this study can be a useful tool for estimating the probability that each polyp is an AN and might be informative for whom screening colonoscopy is performed.

In conclusion, advanced age, male sex, family history of cancer other than colorectal cancer, and smoking may be risk factors for both AN and HRA in the first life time colonoscopy, and aspirin use may be protective factors for AN but not for HRA. The probability of AN in individual polyps could be predicted with the decision tree model of the study. It was found that the important factors in predicting $\mathrm{AN}$ were location, size, and

\section{REFERENCES}

1. Bray F, Ferlay J, Soerjomataram I, Siegel RL, Torre LA, Jemal A. Global cancer statistics 2018: GLOBOCAN estimates of incidence and mortality worldwide for 36 cancers in 185 countries. CA Cancer J Clin. (2018) 68:394424. doi: $10.3322 /$ caac. 21492

2. Arnold M, Sierra MS, Laversanne M, Soerjomataram I, Jemal A, Bray F. Global patterns and trends in colorectal cancer incidence and mortality. Gut. (2016) 66:683-691. doi: 10.1136/gutjnl-2015-310912

3. Lin JS, Piper MA, Perdue LA, Rutter CM, Webber EM, O'Connor E, et al. Screening for colorectal cancer: updated evidence report and systematic review for the US preventive services task force. JAMA. (2016) 315:257694. doi: 10.1001/jama.2016.3332

4. Lengauer C, Kinzler KW, Vogelstein B. Genetic instability in colorectal cancers. Nature. (1997) 386:623-7. doi: 10.1038/386623a0

5. Markowitz SD, Bertagnolli MM. Molecular origins of cancer: molecular basis of colorectal cancer. $N$ Engl J Med. (2009) 361:2449-60. doi: 10.1056/NEJMra0804588

6. Nishihara R, Wu PK. Lochhead T. Morikawa X. Liao ZR. Qian K, et al. Longterm colorectal-cancer incidence and mortality after lower endoscopy. N Engl J Med. (2013) 369:1095-105. doi: 10.1056/NEJMoa1301969 shape of the polyp, and the sex of the subject. Identifying such risk factors in an average individual may help in making tailored decisions in clinical practice.

\section{DATA AVAILABILITY STATEMENT}

The raw data supporting the conclusions of this article will be made available by the authors, without undue reservation.

\section{ETHICS STATEMENT}

The studies involving human participants were reviewed and approved by Seoul National University College of Medicine/Seoul National University Hospital Institutional Review Board (No. 0709-025-218). Written informed consent for participation was not required for this study in accordance with the national legislation and the institutional requirements.

\section{AUTHOR CONTRIBUTIONS}

KC, MP, JP, and SC contributed to the concept and design of the study. EJ, JYS, and JK critically reviewed the research protocol. EJ, JYS, JHS, SY, YK, JY, and SL collected, analyzed, and interpreted the data. KC performed the literature search and critically revised the manuscript. All authors contributed to drafting the manuscript and approved the final version.

\section{ACKNOWLEDGMENTS}

The authors gratefully acknowledge the invaluable assistance of the Statistics and Data Center at Samsung Medical Center and the endoscopists at SNUH Healthcare System Gangnam Center in the application of the surveillance protocol as well as meticulous endoscopy procedures.
7. Shapiro JA, Klabunde CN, Thompson TD, Nadel MR, Seeff LC, White A. Patterns of colorectal cancer test use, including CT colonography, in the 2010 national health interview survey. Cancer Epidemiol Biomarkers Prev. (2012) 21:895-904. doi: 10.1158/1055-9965.EPI-12-0192

8. Wolf AMD, Fontham ETH, Church TR, Flowers CR, Guerra CE, LaMonte SJ, et al.Colorectal cancer screening for average-risk adults: 2018 guideline update from the american cancer society. CA Cancer J Clin. (2018) 68:25081. doi: $10.3322 /$ caac. 21457

9. Qaseem A, Crandall CJ, Mustafa RA, Hicks LA, Wilt TJ, Clinical Guidelines Committee of the American College of Physicians, et al. Screening for colorectal cancer in asymptomatic average-risk adults: a guidance statement from the american college of physicians. Ann Intern Med. (2019) 171:64354. doi: 10.7326/M19-0642

10. Aronchick CA. Bowel preparation scale. Gastrointest Endosc. (2004) 60:10378. doi: 10.1016/S0016-5107(04)02213-8

11. The Paris endoscopic classification of superficial neoplastic lesions: esophagus, stomach, and colon participants in the Paris workshop. Gastrointest Endosc. (2003) 58(6):S3-S43. doi: 10.1016/S0016-5107(03) 02159-X

12. Aaltonen LA, Hamilton SR, World Health Organization, International Agency for Research on Cancer., Pathology and genetics of tumours of 
the digestive system, IARC Press. Oxford University Press Distributor, Lyon Oxford, (2000).

13. Gupta S, Lieberman D, Anderson JC, Burke CA, Dominitz J A, Kaltenbach $\mathrm{T}$, et al. Recommendations for follow-up after colonoscopy and polypectomy: a consensus update by the US multi-society task force on colorectal cancer. Gastroenterology. (2020) 158:1131-53. doi: 10.1053/j.gastro.2019.10.026

14. W.H. Organization. The Asia-Pacific Perspective: Redefining Obesity And Its Treatment (2000).

15. W.H. Organization. Obesity: Preventing And Managing The Global Epidemic: Report Of A WHO consultation on obesity, WHO Consultation on Obesity, World Health Organization, 1998.

16. Breiman L, Friedman J, Olshen RA, Stone CJ. Classification and Regression Trees. Chapman Hall. (1984).

17. European Colorectal Cancer Screening Guidelines Working G, von Karsa L, Patnick J, Segnan N, Atkin W, Halloran S, et al. European guidelines for quality assurance in colorectal cancer screening and diagnosis: overview and introduction to the full supplement publication. Endoscopy. (2013) 45:519. doi: $10.1055 / \mathrm{s}-0032-1325997$

18. Bibbins-Domingo K, Grossman DC, Curry SJ, Davidson KW, Epling JW, Garcia FAR, et al. Screening for colorectal cancer: US preventive services task force recommendation statement. JAMA. (2016) 315:256475. doi: 10.1001/jama.2016.5989

19. Yeoh KG, Ho KY, Chiu HM, Zhu F, Ching JY, Wu DC, et al. The Asiapacific colorectal screening score: a validated tool that stratifies risk for colorectal advanced neoplasia in asymptomatic Asian subjects. Gut. (2011) 60:1236-41. doi: 10.1136/gut.2010.221168

20. Law CW, Rampal S, Roslani AC, Mahadeva S. Development of a risk score to stratify symptomatic adults referred for colonoscopy. J Gastroenterol Hepatol. (2014) 29:1890-6. doi: 10.1111/jgh.12638

21. Kaminski MF, Polkowski M, Kraszewska E, Rupinski M, Butruk E, Regula J, et al. score to estimate the likelihood of detecting advanced colorectal neoplasia at colonoscopy. Gut. (2014) 63:1112-9. doi: 10.1136/gutjnl-2013-304965

22. Tao S, Hoffmeister M, Brenner H. Development and validation of a scoring system to identify individuals at high risk for advanced colorectal neoplasms who should undergo colonoscopy screening. Clin Gastroenterol Hepatol. (2014) 12:478-85. doi: 10.1016/j.cgh.2013.08.042

23. Cai QC, Yu ED, Xiao Y, Bai WY, Chen X, He LP, et al. Derivation and validation of a prediction rule for estimating advanced colorectal neoplasm risk in average-risk Chinese. Am J Epidemiol. (2012) 175:58493. doi: 10.1093/aje/kwr337

24. Ma E, Sasazuki S, Iwasaki M, Sawada N, Inoue M, Shoichiro T, et al. 10Year risk of colorectal cancer: development and validation of a prediction model in middle-aged Japanese men. Cancer Epidemiol. (2010) 34:53441. doi: 10.1016/j.canep.2010.04.021

25. Corley DA, Jensen CD, Marks AR, Zhao WK, de Boer J, Levin TR, et al. Quesenberry, variation of adenoma prevalence by age, sex, race, and colon location in a large population: implications for screening and quality programs. Clin Gastroenterol Hepatol. (2013) 11:172-80. doi: 10.1016/j.cgh.2012.09.010

26. Vatn $\mathrm{MH}$, Stalsberg $\mathrm{H}$. The prevalence of polyps of the large intestine in Oslo: an autopsy study. Cancer. (1982) 49:819-25.

27. Boroff ES, Gurudu SR, Hentz JG, Leighton JA, Ramirez FC. Polyp and adenoma detection rates in the proximal and distal colon. Am J Gastroenterol. (2013) 108:993-9. doi: 10.1038/ajg.2013.68

28. Choi SY, Park DI, Lee CK, Cha JM, Lee SH, Whangbo Y, et al. [Usefulness of polyp and adenoma detection rate in the proximal and distal colon]. Korean J Gastroenterol. (2014) 63:11-7. doi: 10.4166/kjg.2014.63.1.11

29. Tsai FC, Strum WB. Prevalence of advanced adenomas in small and diminutive colon polyps using direct measurement of size. Dig Dis Sci. (2011) 56:2384-8. doi: 10.1007/s10620-011-1598-x

30. Jeong YH, Kim KO, Park CS, Kim SB, Lee SH, Jang BI. Risk factors of advanced adenoma in small and diminutive colorectal polyp. J Korean Med Sci. (2016) 31:1426-30. doi: 10.3346/jkms.2016.31.9.1426
31. Lieberman D, Moravec M, Holub J, Michaels L, Eisen G. Polyp size and advanced histology in patients undergoing colonoscopy screening: implications for CT colonography. Gastroenterology. (2008) 135:11005. doi: $10.1053 /$ j.gastro.2008.06.083

32. Silva SM, Rosa VF, Santos AC, Almeida RM, Oliveira PG, Sousa JB. Influence of patient age and colorectal polyp size on histopathology findings. Arq Bras Cir Dig. (2014) 27:109-13. doi: 10.1590/S0102-672020140002 00006

33. Bas B, Dinc B, Oymaci E, Mayir B, Gunduz UR. What are the endoscopic and pathological characteristics of colorectal polyps? Asian Pac J Cancer Prev. (2015) 16:5163-7. doi: 10.7314/APJCP.2015.16.13. 5163

34. Kim DH, Pickhardt PJ, Taylor AJ. Characteristics of advanced adenomas detected at CT colonographic screening: implications for appropriate polyp size thresholds for polypectomy versus surveillance. AJR Am J Roentgenol. (2007) 188:940-4. doi: 10.2214/AJR.06.0764

35. Yoo TW, Park DI, Kim YH, Kim HS, Kim WH, Kim TI, et al. Clinical significance of small colorectal adenoma less than $10 \mathrm{~mm}$ : the KASID study. Hepatogastroenterology. (2007) 54:418-21.

36. Shapiro R, Ben-Horin S, Bar-Meir S, Avidan B. The risk of advanced histology in small-sized colonic polyps: are non-invasive colonic imaging modalities good enough? Int J Colorectal Dis. (2012) 27:1071-5. doi: 10.1007/s00384-012-1409-7

37. Seo JY, Chun J, Lee C, Hong KS, Im JP, Kim SG, et al. Novel risk stratification for recurrence after endoscopic resection of advanced colorectal adenoma. Gastrointest Endosc. (2015) 81:655-64. doi: 10.1016/j.gie.2014. 09.064

38. Martinez ME, Sampliner R, Marshall JR, Bhattacharyya AK, Reid ME, Alberts DS. Adenoma characteristics as risk factors for recurrence of advanced adenomas. Gastroenterology. (2001) 120:1077-83. doi: 10.1053/gast.2001.23247

39. Shin A, Kim KZ, Jung KW, Park S, Won YJ, Kim J, et al. Increasing trend of colorectal cancer incidence in Korea, 1999-2009. Cancer Res Treat. (2012) 44:219-26. doi: 10.4143/crt.2012.44.4.219

40. Cha JM, Kozarek RA, La Selva D, Gluck M, Ross A, Chiorean M, et al. Disparities in prevalence, location, and shape characteristics of colorectal neoplasia between South Korean and U.S. patients. Gastrointest Endosc. (2015) 82:1080-6. doi: 10.1016/j.gie.2015. 04.018

41. Markowitz AJ, Winawer SJ. Management of colorectal polyps. CA Cancer J Clin. (1997) 47:93-112. doi: 10.3322/canjclin.47.2.93

42. Laird-Fick HS, Chahal G, Olomu A, Gardiner J, Richard J, Dimitrov N. Colonic polyp histopathology and location in a community-based sample of older adults. BMC Gastroenterol. (2016) 16:90. doi: 10.1186/s12876-016-0497-1

Conflict of Interest: The authors declare that the research was conducted in the absence of any commercial or financial relationships that could be construed as a potential conflict of interest.

Publisher's Note: All claims expressed in this article are solely those of the authors and do not necessarily represent those of their affiliated organizations, or those of the publisher, the editors and the reviewers. Any product that may be evaluated in this article, or claim that may be made by its manufacturer, is not guaranteed or endorsed by the publisher.

Copyright (c) 2021 Chung, Park, Jin, Seo, Song, Yang, Kim, Yim, Lim, Kim, Chung and Park. This is an open-access article distributed under the terms of the Creative Commons Attribution License (CC BY). The use, distribution or reproduction in other forums is permitted, provided the original author(s) and the copyright owner(s) are credited and that the original publication in this journal is cited, in accordance with accepted academic practice. No use, distribution or reproduction is permitted which does not comply with these terms. 